\title{
Research on Problems and Prevention of Audit Risk Management Control in Accounting Firms
}

\author{
Zhao Qi \\ Business Administration, Chaohu College, Chaohu, China
}

\section{Email address:}

zhaoqi110@sina.com

\section{To cite this article:}

Zhao Qi. Research on Problems and Prevention of Audit Risk Management Control in Accounting Firms. Science Innovation. Vol. 7, No. 3, 2019, pp. 102-105. doi: 10.11648/j.si.20190703.14

Received: July 13, 2019; Accepted: August 11, 2019; Published: August 27, 2019

\begin{abstract}
In recent years, significant litigation cases have taken place in China's accounting field. Many CPA and CPA firms are involved in economic cases, which have a great impact on society. The common concern in the industry is how to avoid audit risk. This paper first introduces the concept and characteristics of audit risk, and then analyzes the audit risk from the three angles of the audit unit, the accounting firm itself and the CPA, and analyzes the reasons. Finally, from the audit unit, accounting firm itself, CPA three aspects to solve the accounting firm audit risk measures and suggestions, in order to better avoid the audit risk.
\end{abstract}

Keywords: Accounting Firm, Audit Risk, Risk Prevention and Control

\section{会计事务所审计风险管理控制存在的问题及防范研究}

\section{赵祺}

巢湖学院工商管理学院, 巢湖, 中国

\section{邮箱}

zhaoqi110@sina.com

\begin{abstract}
摘要: 近几年以来, 中国会计领域发生重大诉讼案件, 许多注册会计师和会计师事务所涉及经济案件, 对社会有很大 的影响, 业界普遍关心的问题就是如何避免审计风险。本文首先介绍审计风险的概念和特征, 接着从被审计单位、会 计事务所自身、注册会计师三个角度分析会计事务所存在的审计风险，并分析原因。最后从被审计单位、会计事务所 自身、注册会计师三个方面提出解决会计事务所审计风险的措施和建议，以期更好的避免审计风险。
\end{abstract}

关键词: 会计师事务所, 审计风险, 风险防范与控制

\section{1. 引言}

近几年, 国内和国外经常发生严重财务舞弊案件, 特 别危及资本市场的健康发展和提升, 审计职业方面也面临 着信任危机甚至是灭亡。因审计失败而倒闭会计师事务所 有安达信一一国际五大会计公司之一和我国的中天勤, 对 注册会计师这个领域影响很大。同时也使得注册会计师行 业对审计风险有着更加深刻的了解。如何更好的提高审计
风险管理, 规避风险和有效控制, 在工作提高审计效果和 效率, 已经是全世界审计界都应该努力解决的一个重要问 题, 我国也应该跟上全世界的脚步, 在审计风险方面努力 的进行突破。 


\section{2. 审计风险的概念和特征}

\section{1. 审计风险的概念}

对于审计风险的概念, 目前国内和国外审计行业领域 还没有形成一个完全一样的定义国际会计师联合会 (IFAC) 《国际审计准则第6号一风险评估和内部控制》 指出: “审计风险是指审计人员对实质上错报的财务资料 可能提供不适当意见的那种风险、例如, 审计人员在那些 他们所不知道的情况下, 可能对实质上错报的财务报表提 供了无保留意见”。美国注册会计师协会 (AICPA) 认为: “审计风险是审计人员对存在重大错报的财务报表未能适 当地发表自己意见的风险”。我国注册会计师执业准则中 《中国注册会计师审计准则第1101号——财务报表审计 的目标和一般原则》将审计风险定义为: “审计风险是指 财务报表存在重大错报而注册会计师发表不恰当审计意 见的可能性”。[1]

\section{2. 审计风险的特征}

\subsection{1. 审计风险的可控性和客观性}

审计风险的水平可以由审计师的主观努力来控制。虽 然审计风险是无法避免的, 但是审计风险水平高低是可以 控制的。因为审计风险是一种潜在的和可能的损失所以审 计风险的可控性的, 通过自身的努力审计人员可以降低这 种潜在损失发生的数额和可能。

审计风险是客观存在的, 是实际存在的, 不会因为人 们的意志所转移或者消失。现代审计大多采用抽样审计方 法, 由于或多或少的总体特征和样本特征而导致一部分的 错误。[2]因此, 虽然采用抽样审计方法但是也不可能保证 审计结论一定正确, 必定存在一定程度的审计风险。即便 审计人员采用详细认真的审计, 也会由于因为被复杂性的 审计单位经济业务、管理人员的道德品质和审计人员经验 和能力的不足等多种原因, 使得审计意见出现一定程度的 偏差和错误，从而使审计风险客观存在。

\subsection{2. 审计风险的利弊和普遍性}

审计风险对审计人员来讲，既有好的一方面，也有不 好的一方面。审计风险的好处体现在：在当今社会中, 被 审计单位业务过于复杂, 审计人员不可能采取详细的检查, 审计职业存在的前提条件是允许存在一定的审计风险, 如 果不允许审计风险存在, 也许就没有人愿意从事审计职业。 另外, 如果有审计诉讼发生, 审计人员可以通过利用审计 风险来保护自己的利益, 减少自身的损失。同时, 审计风 险也是有不利的一方面, 它是一种潜在存在的损失。若审 计人员所承担的审计风险超过自身的控制能力时, 或者当 审计人员不是特别刻意的控制审计风险时, 它就有可能变 成为现实的审计损失，造成为审计失败。[3]

通过最后的审计结论与预期的偏差将审计风险表现 出来, 但是这样偏差是由多方面因素引起的, 审计活动中 的每一个环节都可能导致风险因素的出现。每一个具体风 险来看, 也是由多方便因素组成的。因此, 审计风险具有 普遍性, 它在审计过程的每一个环节都存在, 哪怕一个环 节的审计出现失误, 最终都会增加审计的风险。

\subsection{3. 审计风险的隐蔽性}

审计风险是客观存在的, 审计人员却不容易轻易做出 精确的判断, 只能依靠经验知识做出精准的判断。审计责 任的存在是审计风险形成的基本因素, 如果审计师不受任 何专业限制, 对自己的工作结果不承担任何责任, 就不会 形成审计风险, 这就决定了审计风险在一定时期具有潜在 性。

\section{3. 会计师事务所审计风险的问题分析}

\section{1. 来自会计师事务所的审计风险}

\subsection{1. 组织形式}

在会计师事务所的发展史上, 合伙是会计师事务所 最为古老的组织形式。合伙制会计师事务所实行的无限 责任,一方面加大了注册会计师的职业风险, 促使其自我 约束、谨慎执业; 另一方面,合伙制因其共同经营、共担风 险、共享利润以及决策灵活的特点而凸显了执业者的个 人角色, 长期以来其一直是会计师事务所的首选组织形 式。但是现在我国大部分的会计事务所大部分是有限责 任公司的形式, 这种形式的弊端特别的多, 主要的体现 是:不管什么样的审计报告都敢写, 基本没有风险意识, 混淆意识严重, 有些事务所的股东特别的多, 导致大家 责任分工不明确, 导致大家工作的状态不佳, 所以控制 风险的积极性也不热心, 缺乏对未来的长远计划。[4]很 多会计师事务所喜欢这种组织形式主要是大家都不愿去 承担风险, 因为会计市场的竞争激烈, 不确定的因素太 多, 制度也不是特别的健全, 监管也不是很到位, 弊端 较多。

\subsection{2. 人力资源的结构}

会计师事务所最宝贵的财务就是人力资源。如果出现 财务舞弊的问题那肯定是人为的因素, 这其中也包括会计 事务所的人。而这一切直接取决于执业人员是否具备良好 的道德标准和知识背景, 是否不断地吸收和补充新知识, 以及会计师事务所对执业人员的管理。因此, 会计师事务 所甚至整个民间审计行业要健康发展, 人力资源的管理都 是核心因素。[5]目前, 在我国一些会计师事务所人力资源 结构不合理, 一方面有些人员执业素质较差, 不合适从事 注册会计师工作, 但又很难将其辞退; 另一方面高素质的 执业人员太少, 无法按执业的实际需要合理设置工作岗位 和配备执业人员。

\subsection{3. 内部审计质量监督制度}

会计师事务所内部质量控制的关键是执行业务过程中 的质量控制, 它关系到出具业务报告的质量、为客户服务的 水准, 关系到事务所的生存和发展。会计师事务所应加强内 部质量监管, 设置质量管理部和总会计师室, 按照财政部和 中注协有关质量控制准则的要求, 制定了相应的质量管理制 度如: 严格检查重要程序的执行情况, 加强审计底稿编制的 规范化, 使复核工作程序化等, 齐心协力、脚踏实地地抓质 量, 才能增强员工的质量意识, 有效防范审计风险。[6] 


\section{2. 来自注册会计师的审计风险}

\subsection{1. 专业的担任能力}

从事上市公司审计工作的事务所可能不具备相应的 专业胜任能力, 但却出于经营收益的考虑, 接受业务复杂 的上市公司的委托，从事对该公司审计工作。审计过程中 由于其不能对特殊复杂的业务核算处理和被审单位提供 的信息的可靠性做出正确的判断, 忽略了错误或舞弊的存 在，加大了审计风险。

\subsection{2. 对被审计单位的了解情况}

只有对被审计单位有一个全面的掌握，才能够正 确地评估审计风险, 合理地确定审计风险的大小。评 估被审计单位的经济状况, 有赖于审计人员对被审计 单位的经营及其产业的了解, 包括经济环境及竞争状 况、被审计单位的财务状况、管理层状况及内部控制 制度等方面。

\subsection{3. 审计程序及方法}

受审计成本效益的制约, 注册会计师在设计和执 行审计程序时, 往往会舍弃一些耗时费力的审计程序, 这就可能导致一些影响审计意见正确性的程序未被执 行, 从而使审计意见失真。[7]此外, 由于审计技术条 件的限制, 对被审项目的审查仍以抽查审计为主, 对 样本的选择更多地放在分析性程序和经验判断所选定 的项目上, 这样导致了所审查的项目不一定能科学、 有效地代表总体的特征, 使审计结论与事实之间可能 出现偏差。[8]

\section{3. 来自被审计单位的审计风险}

\subsection{1. 财务信息披露的真实程度}

被审计单位的财务信息, 财务报表的表达是否真 实可靠, 是否存在非故意的错报或漏报情形, 是否存 在原始凭证和会计数据的计算、抄写错误; 对事实的 疏忽和误解；对会计政策的误用等都是审计风险产生 的源泉。

\subsection{2. 企业治理的结构}

在我国目前的公司中, 尤其是上市公司, 公司董事 并未受到来自股东大会的真正制约, 董事会无法起到对 公司经营管理当局的控制作用。这种公司法人治理结构 失效造成的会计师事务所与被审计单位之间审计关系的 扭曲, 破坏了注册会计师的独立性, 加大了审计风险产 生的可能性。直接降低了社会公众对注册会计师审计的 信赖程度。[9]

\subsection{3. 内部控制制度}

内部控制制度主要包括组织结构及职责分工控制、授 权批准控制、会计记录控制、资产保护控制、职工素质控 制、预算控制、风险控制和业绩报告控制等方面。被审计 单位是否设有内部审计机构及其是否对董事会负责; 是否 在报告期对企业内部和各个子公司进行过内部审计并形
成内部审计报告; 内部审计的决定能否正常地执行; 内部 审计能否独立、客观地开展审计工作：内部审计报告是否 会因受到公司管理层的授意、指使而失真等等都与审计风 险的产生联系在一起。

\section{4. 会计师事务所审计风险的防范措施}

\section{1. 从会计师事务所的角度进行审计风险的防控}

\subsection{1. 进行体制的改革}

根据《注册会计师法》的规定，我国可以设立有限责 任制会计师事务所和合伙制的会计师事务所。这两种体制 均存在明显的弊端, 缺乏一定的合理性和适用性。目前, 国际注册会计师职业界普遍采用的组织形式是有限责任 合伙制。这种形式与有限责任制相比, 提高了注册会计师 的违规成本, 促使注册会计师增强了风险意识, 提高了其 规避风险的能力。[10]这种形式与合伙制的形式相比, 其 合伙人不必为别人的错误或舞弊行为付出惨重的代价, 解 除了后顾之忧, 有利于会计师事务所的稳定与发展。会计 师事务所通过体制改革, 就能拥有一个健康发展的审计风 险管理主体，将有利于审计风险的管理。

\subsection{2. 促进规模发展}

在国外, 由于形成了比较有序的竞争市场, 会计师事 务所可以根据自己的能力来承接客户。而我国的会计师事 务所数量多, 规模小, 就事务所本身的实力、人员的数量 和素质等等来看, 事务所根本达不到承接大项目的要求。 从审计风险管理的角度和会计师事务所的长远发展来看, 扩大事务所规模, 进行事务所规模化经营是一个趋势。事 务所的规模扩大, 可以优化资源配置, 更好的利用注册会 计师的专业能力, 使事务所有能力承接大型的业务和开展 新的业务, 增强风险抗拒能力。

[11]

\subsection{3. 采用合理的审计方法}

会计师事务所采用合理的审计方式和实施充分的审 计程序是控制审计风险的有效措施。风险导向审计模式是 将客户置身于一个大的经济环境中, 从企业所处的内外部 条件等各个方面来分析和评估审计的风险水平, 把客户的 经营风险加入到其自身的风险评价中去, 把风险意识贯穿 到审计的全过程, 要求审计人员实施足够的审计程序来减 少审计风险的产生, 并通过审计程序把审计风险降低到审 计人员可以接受的水平。在我国, 对于风险导向审计模式 尚处于初步了解和认识的阶段, 有部分会计师事务所在对 大型企业或上市公司进行审计时。已经尝试着对于风险导 向审计模式的运用。从整个注册会计师行业来看, 仍处于 遵循制度导向审计模式阶段, 但可以肯定地说。在不远的 将来用现代风险导向审计模式取代传统的制度导向审计 模式已是必然。风险导向审计做到了资源的优化配置, 能 够把有限的资源集中到应该重点对待的地方, 它能更有效 的控制和提高审计的效率和效果, 有利于提高审计人员的 风险意识, 减轻审计人员的责任, 审计人员由被动的承受 审计风险到主动地控制审计风险。 


\section{2. 从注册会计师角度进行风险防范}

\subsection{1. 注重审计的独立性}

独立性是指会计师事务所和注册会计师独立于客户 和其他单位之外, 与客户和其他单位免除任何利益关系, 以客观、公正的原则和立场分析、判断和处理问题。注册 会计师与被审单位的关系密切, 肯定会影响审计的独立性。 [12]目前我国的审计职业界对客户提供的非审计服务还不 是很多, 像管理咨询服务, 因此对同一客户同时提供审计 和非审计服务所引起的审计风险并不很明显。但我们仍应 吸取有关经验教训, 加以足够重视。

\subsection{2. 提高专业胜任的能力}

专业胜任能力是指注册会计师应具备扎实的专业理 论知识和丰富的实践经验, 并具有足够的职业判断能力和 职业谨慎态度。由于目前我国注册会计师资格考试的门槛 较低, 取得了注册会计师的执业资格, 并不代表其具有了 执业能力。注册会计师提供的服务范围越来越广, 服务的 对象越来越复杂, 对注册会计师专业能力的要求也越来越 高, 因此应当加强相关领域的人员录用工作以获得所需要 的技术, 同时加强后续教育和培训, 力争培养一批既懂财 会知识又精通经济、工程、法律、计算机等各方面的人才, 提高注册会计师的工作能力。[13]此外, 要加强注册会计 师的职业道德教育, 改变审计职业界面临的诚信危机。

\subsection{3. 接受委托要充分了解被审计单位}

第一客户品行端正, 信誉良好, 客户具有正直的品格, 则出现差错和舞弊行为的可能性就小, 固有风险就低; 反 之, 固有风险就很高, 扩大审计测试的规模, 使总体审计 风险降低到社会可接受的水平内。第二事务所应尽可能详 细了解委托单位的业务状况注册会计师面临着许多形形 色色的行业, 每个行业都有其经营特点, 被审计单位的经 济业务越复杂, 审计的相对风险就越大, 有时即使注册会 计师能搜集到很多有说服力的审计证据, 但也很难揭示经 济业务的实质, 因此, 在承接业务时, 注册会计师应充分 估计这一风险, 采取相应的措施防患于未然。[14]第三对 财务状况不佳的委托单位要尤其加以注意过去大部分审 计诉讼案都集中在陷入财务困境的审计客户。当其面临破 产或偿债出现问题时股东或债权人总想把损失转嫁他人, 故这种客户的审计风险更大, 执行审计时更要提高警惕。

风险无处不在, 它与事务所的整个生命周期共存, 从 事务所诞生到其结束的整个历程都伴随着风险, 是任何一 个会计师事务所都必须面对的、无法回避的现实存在。虽 然风险的特性决定了会计师事务所不可能完全消除风险 及由此而生的损失风险, 但是可以采取措施防范和化解风 险。因此, 会计师事务所应变被动承担风险为积极主动地 管理风险, 即利用科学、系统和规范的方法, 对事务所风 险进行识别、衡量和控制。通过真正具有全局性、前瞻性 的方法去管理所有关键性的风险, 从而使会计师事务所能 够在变动不定的经济环境中最大限度地利用机遇人避免 损失，在激烈的市场竞争中确立自身的优势。[15]

\section{5. 结论}

从会计师事务所建立伊始, 审计风险就伴之而生, 其 存在于事务所的整个生涯中。但审计风险又是不可避免的 存在, 这是由其特质所决定的。会计事务所想要避免被审 计风险击垮情况的出现, 一味的逃避是没有用的, 只有积 极主动地去管理风险, 采用合理有效的措施去降低审计风 险发生的概率, 或是改善在审计风险发生后的损失状况。 因此, 会计事务所要加强自身的风险管理意识, 加强对审 计风险的认识学习, 才能在审计风险发生时, 最大限度的 利用自身优势, 化解事务所的困难, 在激烈的市场竞争者 留存下来。

\section{参考文献}

[1] 赵红丽. 现阶段会计事务所面临的审计风险几防范措施 [J]. 行政事业资产与财务, 2017,(27):16-18。

[2] 梁珊. 论审计风险及防范控制[J].产业与科技论坛. 2018,(1)： $24-26$ 。

[3] 成焕玲.我国内部审计存在的问题及对策[]].新西部（下半 月） $2015,(4): 15-17$ 。

[4] 杜雪, 我国内部审计存在的问题及对策[J].企业技术开 发.2016,(11): 12-13。

[5] 贾莉. 论审计风险的防范和控制[J].经营管理者, 2016,(5): $18-20$ 。

[6] 谢小芳.会计事务所审计风险防控研究 [J]. 管理观察, 2016,(5):54-56。

[7] 李丹.注册会计师审计失败问题研究[J].质量探索.2016,(2): $42-46$.

[8] 刘风环. 我国会计师事务所审计风险管理中存在的问题及 对策[J].企业研究, 2013,(4): 12-14。

[9] 焚翠云, 刘炜.会计师事务所审计风险防范与控制[J].内蒙古 科技与经济，2013,(5)：34-36。

[10] 刘军.企业内部审计存在的问题和改善措施 [J]. 科技 风.2014,(9): 42-43。

[11] 商明莣, 张一诺.会计师事务所审计风险的现状与对策研究 [J].知识经济.2018,(7): 18-20。

[12] 夹姝慧,刘晶晶. 会计师事务所合并对审计独立性的作用分 析 [J]. 中国证券期货.2010,(10): 31-34。

[13] 任铁彦. 国内内资会计师事务所的发展之路一一合并专业 化经营[J]. 中国市场.2011,(22): 25-27。

[14] 覃易寒. 中小会计师事务所专业化经营的几点思考 [J]. 财 经界.2010,(3): 11-15。

[15] 孙蕾. 建立会计师事务所审计质量评价体系 [J]. 知识经 济.2011,(15): 21-24。 